\title{
Electoral Rules and Minority Representation in U.S. Cities
}

\section{Citation}

Trebbi, Francesco, Philippe Aghion, and Alberto Alesina. 2008. Electoral Rules and Minority Representation in U.S. Cities. Quarterly Journal of Economics 123, no. 1: 325-357.

\section{Published Version}

http://dx.doi.org/10.1162/qjec.2008.123.1.325

\section{Permanent link}

http://nrs.harvard.edu/urn-3:HUL.InstRepos:4551793

\section{Terms of Use}

This article was downloaded from Harvard University's DASH repository, and is made available under the terms and conditions applicable to Other Posted Material, as set forth at http:// nrs.harvard.edu/urn-3:HUL.InstRepos:dash.current.terms-of-use\#LAA

\section{Share Your Story}

The Harvard community has made this article openly available.

Please share how this access benefits you. Submit a story.

Accessibility 


\title{
ELECTORAL RULES AND MINORITY REPRESENTATION \\ IN U.S. CITIES*
}

\author{
Francesco TRebBi \\ PhiLIPPe AGHion \\ Alberto Alesina
}

\begin{abstract}
This paper studies the choice of electoral rules and in particular the question of minority representation. Majorities tend to disenfranchise minorities through strategic manipulation of electoral rules. With the aim of explaining changes in electoral rules adopted by U.S. cities, particularly in the South, we show why majorities tend to adopt "winner-take-all" city-wide rules (at-large elections) in response to an increase in the size of the minority when the minority they are facing is relatively small. In this case, for the majority it is more effective to leverage on its sheer size instead of risking conceding representation to voters from minority-elected districts. However, as the minority becomes larger (closer to a fifty-fifty split), the possibility of losing the whole city induces the majority to prefer minority votes to be confined in minority-packed districts. Single-member district rules serve this purpose. We show empirical results consistent with these implications of the model in a novel data set covering U.S. cities and towns from 1930 to 2000 .
\end{abstract}

\section{INTRODUCTION}

The Voting Rights Act (VRA) of 1965 was meant to protect the right to vote for racial minorities, especially in the South. In fact, in a reasonably short time, it resulted in a massive reinfranchisement of black voters through an unprecedented effort of voter registration. White majorities in cities of the South reacted strategically to this federal legislation by changing the electoral rules of their cities in order to minimize minority representation. They only partially succeeded. Had they not been kept in check by judicial intervention, they would have engaged in even more openly strategic manipulation of rules. This paper presents evidence of such strategic manipulation both around the time of the introduction of the VRA and in the after-VRA period.

\footnotetext{
* We thank Matilde Bombardini, Gary Chamberlain, John Friedman, Edward Glaeser, Richard Holden, Caroline Hoxby, David Lucca, James Robinson, and John Wallis for useful comments and suggestions. We are grateful to participants of the CIAR meetings in Toronto and seminars at Brown University, Harvard University, the London Business School, Princeton University, Stockholm University, the University of British Columbia, the University of Chicago Graduate School of Business, and the University of Maryland. Andrea Asoni, Dilyan Donchev, Laura Serban, and Radu Tatucu provided excellent research assistance. Trebbi acknowledges financial support from the Social Sciences Research Council and from the University of Chicago Graduate School of Business. A previous version circulated under the title "Choosing Electoral Rules: Theory and Evidence from U.S. Cities."

(C) 2008 by the President and Fellows of Harvard College and the Massachusetts Institute of Technology.
}

The Quarterly Journal of Economics, February 2008 
The two traditional voting rules in American cities are atlarge elections, where the majority at the city level elects the representatives on the city council, and district systems, where representatives are chosen in districts or local wards. Proportional representation systems were tried earlier in the past century and then discarded precisely because they favored minority representation (racial and left wing/socialist) too much. ${ }^{1}$ In this paper we show (in theory and then empirically) that white majorities expecting an increase in black votes after the Voting Right Act adopted at-large electoral rules when the black minority in the city was relatively small, in order to win all seats. However, if the minority share was larger (closer to a fifty-fifty split), the possibility of losing the whole city induced the white majority to confine black votes to minority-packed districts and single-member districts: electoral rules serve this purpose. ${ }^{2}$

This paper provides a "positive" model of choice of electoral rules. We do not study how rules should be chosen behind a veil of ignorance to maximize social welfare, but how a majority knowing that it may remain such or face a chance of loosing would choose rules in its favor. Therefore the general point raised by this paper is that voting rules are hardly exogenous and are chosen strategically, although a vast literature has taken them as exogenous or predetermined and studied their effects on policy choices. ${ }^{3}$ In earlier work we had studied related issues in a cross section of countries (Aghion, Alesina, and Trebbi 2004). In the present paper we study U.S. cities, which are an especially interesting case for three reasons. First, it is quite compelling to identify the "majority" with the whites and the "minority" with racial "minorities."

1. See for instance the discussion in Alesina and Glaeser (2004) and the references cited therein.

2. Manipulation of electoral rules is not a prerogative exclusive of American cities. For a discussion of electoral rules and racial politics in elections in India see Pande (2003). Alexander (2004, p. 211) describes in detail the 1947 Gaullist manipulations of electoral rules in France. In the Paris area, where the Gaullist alliance was weak, they introduced proportional representation; in rural areas, where the alliance was strong, they introduced plurality rule. Kreuzer (2004, p. 229 ) describes strategic manipulation in Germany. One could go on.

3 . For a discussion of the effects of electoral rules taken as predetermined or exogenous see Lijphart (1994) and Persson and Tabellini (2003) for a sample of democratic countries and Baqir (2002) for a cross section of U.S. cities. See also Alt and Lowry (1994), Poterba (1994), and Bohn and Inman (1996), among others. Mulligan, Gil, and Sala-i-Martin (2004) offer a dissenting view, namely that policies are determined by lobbying pressures that are not much affected by institutional forms of government.

4. For discussion of the importance of race in American local politics, see for instance Hacker (1992), Huckfeld and Kohfeld (1989), Wilson (1996), and Alesina, Baqir, and Hoxby (2004). 
Second, the VRA offers an ideal "experiment" of a change in legislation at the federal level that prompted strategic adaptation of local rules. Third, U.S. cities present substantial cross-sectional and time variation in their electoral rules.

This "positive" and strategic approach to models of voting rules is relatively recent and rare ${ }^{5}$ because most of the literature on constitutional choice of voting rules is normative, starting from the work of Hayek (1960) and Buchanan and Tullock (1962). ${ }^{6}$ A normative approach usually characterizes works in political science as well, with some notable exception such as Lipset and Rokkan (1967), Riker (1986), and several essays in Colomer (2004).

The paper is organized as follows. Section II develops a simple formal setup. Section III describes the institutional context of U.S. city governments and introduces our data. Section IV presents our empirical results. The last section concludes.

\section{A Model of the Choice of Electoral Rules}

\section{II.A. Basic Setup}

There are two groups of voters in a city, whites $(W)$ and blacks (B). The initial relative size of the group of blacks is $1 / 2>\pi>0$, so that the size of the larger white group is $(1-\pi)$. The whites are, initially at least, a majority and they are those who choose the electoral rule for the city. (We call the choice of the electoral rule the "constitution.") The population is equally spread over three (exogenously apportioned ${ }^{7}$ ) electoral districts, numbered $1,2,3$, each with $M$ individuals, and the city council consists of three seats. The initial numbers of black and white voters in each district are given by $B_{i}$ and $W_{i}$ for $i=1,2,3$. We assume that $W_{1}=M$ and $W_{2}=W_{3}=(1 / 2+z) M$, where $z$ is a real number between $-1 / 4$ and $1 / 2$, which ensures that $0<\pi<1 / 2$, because

$$
z=\frac{1-3 \pi}{2} \text {. }
$$

5. Alesina and Glaeser (2004) discuss how the choice of alternative electoral rules, which are themselves associated with different policy choices over the welfare state, is indeed the result of strategic constitutional choices. See for instance the work of Acemoglu and Robinson (2006) on the origin of democratic institutions.

6. For a survey of the literature on constitutional theory, see Voigt (1997).

7. The model will abstract from gerrymandering of the electoral districts and the vast literature on the matter. On gerrymandering, see Cox and Katz (2002) and Friedman and Holden (2005). 
The parameter $z$ is a shift term that makes it possible to vary the initial number of black voters in a district and links the citywide racial composition to the district-wide racial composition. The white majority chooses the electoral rule, through which a three-member council is elected. After the constitution is chosen, there is a shock to the composition of voters in the city, which the electoral rule cannot be made contingent upon. ${ }^{8}$ More formally, during the interim phase (defined as the time span between the choice of electoral rule and the election of the council), an exogenously given mass $L_{N}$ of new black voters join the polity, with $L_{N}=\alpha M$, where $\alpha$ is a random variable uniformly distributed between 0 and an upper bound $\bar{\alpha} \in(1,2)$. Half of the newcomers locate in district 2 , and half in district 3 .

Different compositions of the council imply different policies, and therefore different ex post payoffs for the white. $\underline{r}$ (resp. $u_{0}$ and $\bar{r}$ ) is the utility level of a white agent when there are no (resp. one and two) white representative(s) on the council. The ex ante expected utility of a white constitution writer can then be expressed as

$$
U_{w}=\left(1-p_{0}-p_{1}\right) \bar{r}+p_{1} u_{0}+p_{0} \underline{r}, \quad \bar{r}>u_{0}>\underline{r},
$$

where $p_{j}$ denotes the probability that $j$ council representatives are white in the interim stage. Thus, having some representation is better than having none at all, ${ }^{9}$ and, in general, voters' preferences are increasing in their electoral representation. The electoral rule chosen by the white voters determines the value of $p_{0}$ and $p_{1}$. Summarizing: (1) the electoral rule is chosen by the white group; (2) new black voters join the polity and elections determine a given composition of the council; (3) payoffs realize.

\section{II.B. Electoral Rules and Expected Utilities}

With an eye to the case of American cities, we now study two alternative electoral rules. The first one, "at-large" (AL), allocates all seats to the party that wins more than fifty percent of the votes of the entire city. The second rule, "single-member district rule" (SD), requires that each candidate run in a particular district

8. See Laffont (2000) and Aghion and Bolton (2003) for a detailed discussion of this "incomplete contract" approach to constitutions in political economy.

9. See Alesina and Rosenthal (1995) for a legislative model and an extensive discussion of this assumption and a comparison with alternatives. 
and obtain a majority of votes in that district. These are reasonable approximations of the electoral rules in U.S. cities, although details of electoral formulae vary considerably across municipalities. Given our assumptions on the group composition of the three districts, $p_{1}=0$ under the AL rule, and $p_{0}=0$ with the SD rule. Under the at-large rule the ex ante expected utility of constitution writers in the $W$ group is

$$
U_{W}^{\mathrm{AL}}=p_{0}^{\mathrm{AL}} \underline{r}+\left(1-p_{0}^{\mathrm{AL}}\right) \bar{r}=\bar{r}-p_{0}^{\mathrm{AL}} \Delta,
$$

where $\Delta=\bar{r}-\underline{r}$ is the loss from losing the majority, and $p_{0}^{\mathrm{AL}}=$ $\operatorname{Pr}(\alpha>1+4 z)$ is the probability of the whites losing the majority under AL. ${ }^{10}$ Substituting for $z$ as a function of $\pi$ in $p_{0}^{\mathrm{AL}}$ using (1), the ex ante expected loss of the whites (relative to the bliss point $\bar{r})$ under the $\mathrm{AL}$ rule is equal to $L_{W}^{\mathrm{AL}}=p_{0}^{\mathrm{AL}} \Delta=(1-(3 / \bar{\alpha})(1-$ $2 \pi))^{+} \Delta$, where we use the notation $x^{+}=\max \{x, 0\}$. Under the SD rule council seats are allocated at the district level. The probability $p_{1}^{\mathrm{SD}}$ of the blacks winning a majority of two seats is equal to the probability that districts 2 and 3 are won by the blacks. Thus the ex ante utility of the whites under the single-member district rule can be expressed as

$$
U_{W}^{\mathrm{SD}}=p_{1}^{\mathrm{SD}} u_{0}+\left(1-p_{1}^{\mathrm{SD}}\right) \bar{r}=\bar{r}-p_{1}^{\mathrm{SD}} \delta,
$$

where $\delta=\bar{r}-u_{0}$ is the constitution writers' loss from losing the majority. Substituting for $z$ in the probability $p_{1}^{\mathrm{SD}}=\operatorname{Pr}(\alpha>4 z),{ }^{11}$ and using (1), the ex ante expected loss of white constitution writers under the $\mathrm{SD}$ rule is equal to $L_{W}^{\mathrm{SD}}=p_{1}^{\mathrm{SD}} \delta=(1-(2 / \bar{\alpha})(1-$ $\left.3 \pi)^{+}\right)^{+} \delta$.

\section{II.C. The Size of Minorities and the Choice of Electoral Rule}

Ex ante in the constitutional stage, the whites choose the electoral rule that minimizes the expected loss $L_{W}$. If initially the whites command a very large majority of votes, the constitution writers do not fear they can lose the majority under either rule; thus they are indifferent between the two rules. As the relative size of the blacks increases, however, at some point it becomes preferable for the whites to move to $\mathrm{AL}$ in order to reduce the

10. This probability is obtained by considering $p_{0}^{\mathrm{AL}}=\operatorname{Pr}\left(B_{1}+B_{2}+B_{3}+L_{N}>\right.$ $W_{1}+W_{2}+W_{3}$ ).

11. This is the probability that blacks win a two-seats majority, or $p_{1}^{\mathrm{SD}}=$ $\operatorname{Pr}\left(B_{3}+(1 / 2) \alpha M>W_{3}\right)=\operatorname{Pr}(\alpha>4 z)$. 
power of the black voters in districts 2 and 3 by confronting them with the whole pool of white voters, including those in district 1. Doing so allows the whites to preserve their majority in the council. When the fraction of blacks reaches the point where it becomes impossible to ensure that for every realization of $\alpha$ they might become the new majority, moving to the SD rule allows the whites to limit their possible losses: as $\pi$ becomes sufficiently close to $1 / 2$, the risk of losing all three districts and thereby incurring the large loss $\Delta$ makes the whites prefer a SD system. In fact SD guarantees the whites at least 1 seat on the council-and thereby limits their loss to $\delta<\Delta$, given that in this case black voters are restricted to commanding districts 2 and 3 only. More formally:

Proposition 1. a. Both rules, AL and SD, involve no utility loss to whites when $\pi \in(0,1 / 3-\bar{\alpha} / 6)$; b. if $\Delta>\delta$, then there exists a unique cut-off point $\widehat{\pi} \in(1 / 3-\bar{\alpha} / 6,1 / 2)$ such that $L_{W}^{\mathrm{AL}}<L_{W}^{\mathrm{SD}}$ if $\pi \in(1 / 3-\bar{\alpha} / 6, \widehat{\pi})$ and $L_{W}^{\mathrm{AL}}>L_{W}^{\mathrm{SD}}$ if $\pi \in(\widehat{\pi}, 1 / 2)$; c. if $\Delta=\delta$, then for all $\pi \in(1 / 3-\bar{\alpha} / 6,1 / 2)$ the AL rule dominates the SD rule.

Proof. In the Appendix.

Figure I represents graphically the loss functions $L_{W}^{\mathrm{AL}}$ and $L_{W}^{\mathrm{SD}}$, where $\pi_{0}^{\mathrm{AL}}$ (resp. $\pi_{0}^{\mathrm{SD}}$ ) is the size of the minority at which the expected loss under AL (resp. SD) becomes positive.

\section{II.D. $N$ Districts and Mixed Systems}

We now consider two empirically relevant generalizations of the problem. Suppose that the population is equally spread over $N$ electoral districts, with $M$ individuals in each, which elect a council of size $N$. We maintain a distinction between two types of districts: districts with $W_{1}=M$ and districts with $W_{2}=(1 / 2+z)$ $M$, where $W_{j}$ denotes the number of whites in a type- $j$ district. Type 1 districts are white, whereas type 2 districts are an ex ante identical mix of whites and blacks. There are $N_{1}$ type- 1 districts; therefore $N_{2}=N-N_{1}$, and $N_{1}<N_{2}$. During the interim phase a mass $\alpha M$ of black newcomers arrives, with $\alpha \sim U[0, \bar{\alpha}]$ and $\bar{\alpha}<$ $N$. Assume that the whites' utility $u(\cdot)$ is defined over the share of seats won, where we indicate $\Delta=u(1)-u(0)$ and $\delta=u(1)-$ $u\left(N_{1} / N\right)$, following the notation of Proposition 1. Proposition 1 then generalizes to the $N$-district case: namely, we can show that there exist a first cutoff point $\pi_{0}^{\mathrm{SD}} \in(0,1 / 2)$ such that there is no utility loss for the whites in $\left(0, \pi_{0}^{\mathrm{SD}}\right)$ under any rule, and a second 


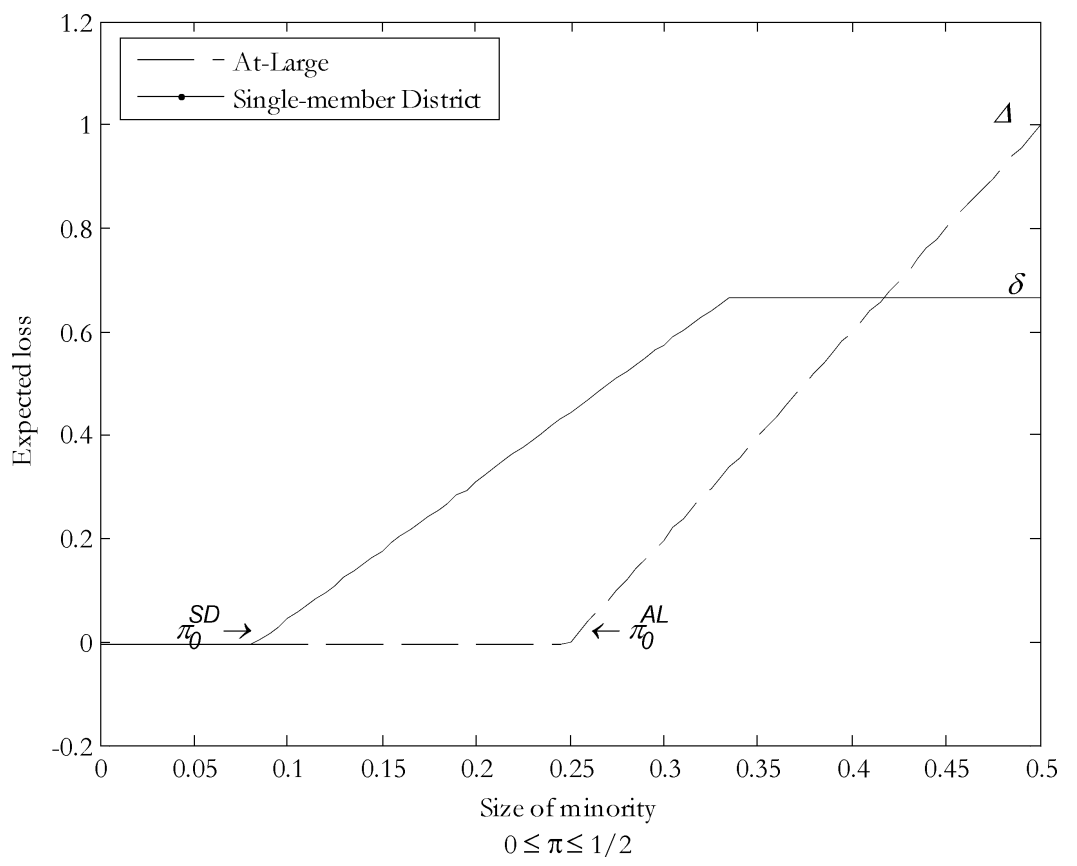

Figure I

Expected Loss under Different Electoral Rules as a Function of $\pi$

cutoff point $\hat{\pi} \in\left(\pi_{0}^{\mathrm{AL}}, \frac{1}{2}\right)^{12}$ such that expected losses under the two rules $\mathrm{AL}$ and SD satisfy

$$
L_{W}^{\mathrm{AL}}<L_{W}^{\mathrm{SD}} \text { if } \pi \in\left(\pi_{0}^{\mathrm{SD}}, \hat{\pi}\right) ; \quad L_{W}^{\mathrm{AL}}>L_{W}^{\mathrm{SD}} \text { if } \pi \in\left(\hat{\pi}, \frac{1}{2}\right) .
$$

Consider now the case of mixed electoral rules for risk-averse white voters. Consider a city with a council of size $N_{\mathrm{TOT}}=\rho N$. Let us now assume $\rho>1$ to allow mixed systems: at least one representative for each single-member district and $N_{\mathrm{AL}}>0$ atlarge representatives. Assume whites' preferences to be defined again over the share of seats won on the council. In a setup with risk-neutral agents, it is never optimal to have mixed systems involving both single-district and at-large councilmen: either AL or SD offers the highest expected number of winning seats. Although a risk-neutral white agent considers exclusively the expected seat-share and has no incentive to convexify, a risk-averse

12. Where $\pi_{0}^{\mathrm{AL}}=(1 / 2)(1-\bar{\alpha} / N)>\pi_{0}^{\mathrm{SD}}=\left(N_{2} / 2 N\right)\left(1-\bar{\alpha} / N_{2}\right)$. 


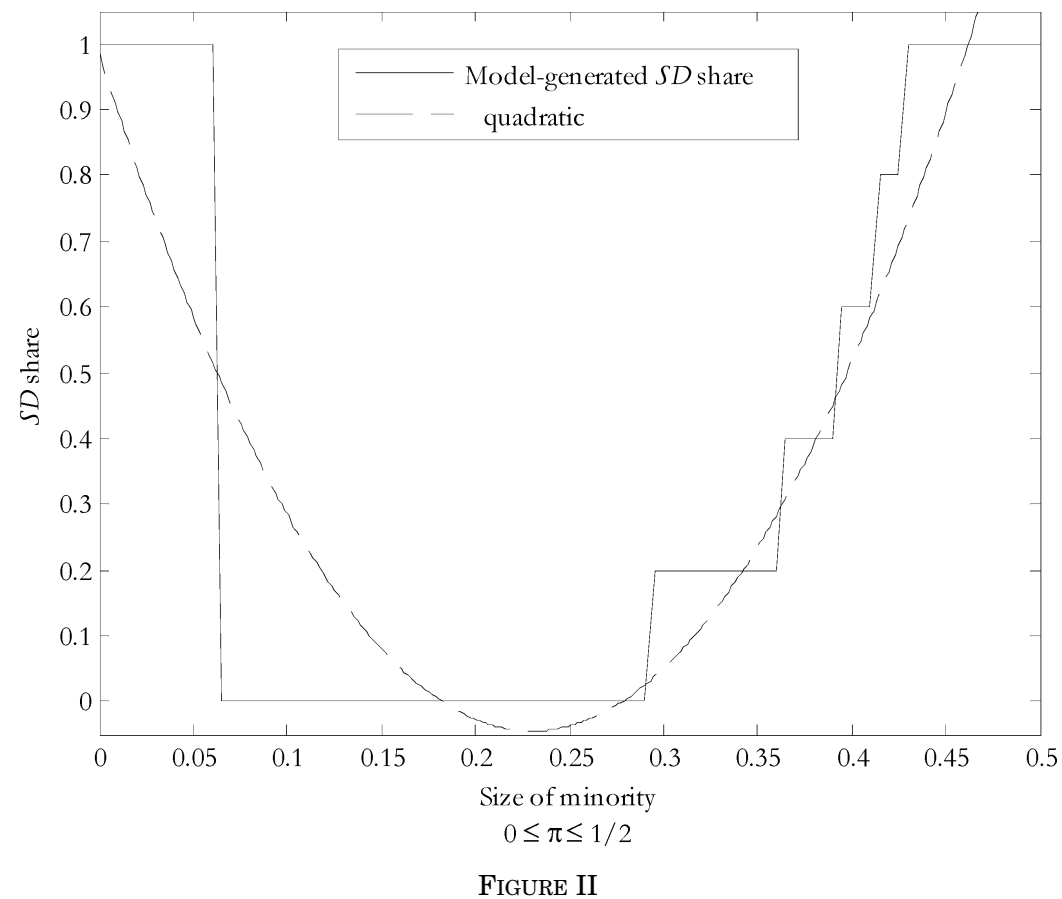

Choice of SD Seats Share as Function of $\pi$

constitutional writer may find it useful to reduce the risk of running pure at-large elections when the opportunity of winning safer single-district seats is available. The following proposition presents this result more formally:

Proposition 2. Consider a city of $N$ districts, council of size $N_{\text {TOT }}$, and black newcomers' arrival $\alpha M, \alpha \sim U[0, \bar{\alpha}], N_{1}<\bar{\alpha}<N$. If the white constitutional writers are risk-averse with utility $u(\cdot), u^{\prime}>0, u^{\prime \prime}<0$, defined over the share of seats won, then there is an interval $\left(\pi_{3}, \pi_{4}\right), \pi_{4}<1 / 2$, and a mixed system with $N_{\mathrm{SD}}>0$ single-district seats and $N_{\mathrm{AL}}>0$ at-large seats for which $U_{W}^{\mathrm{AL}}<U_{W}^{\mathrm{MX}}$ and $U_{W}^{\mathrm{SD}}<U_{W}^{\mathrm{MX}}$ if $\pi \in\left(\pi_{3}, \pi_{4}\right)$, where $U_{W}^{\mathrm{AL}}$ is the expected utility under $\mathrm{AL}, U_{W}^{\mathrm{MX}}$ is the expected utility under a mixed system, and $U_{W}^{\mathrm{SD}}$ is the expected utility under SD.

Proof. In the Appendix.

Figure II reports a numerical example of the optimal share of single-member district councilmen as a function of the ex ante size 


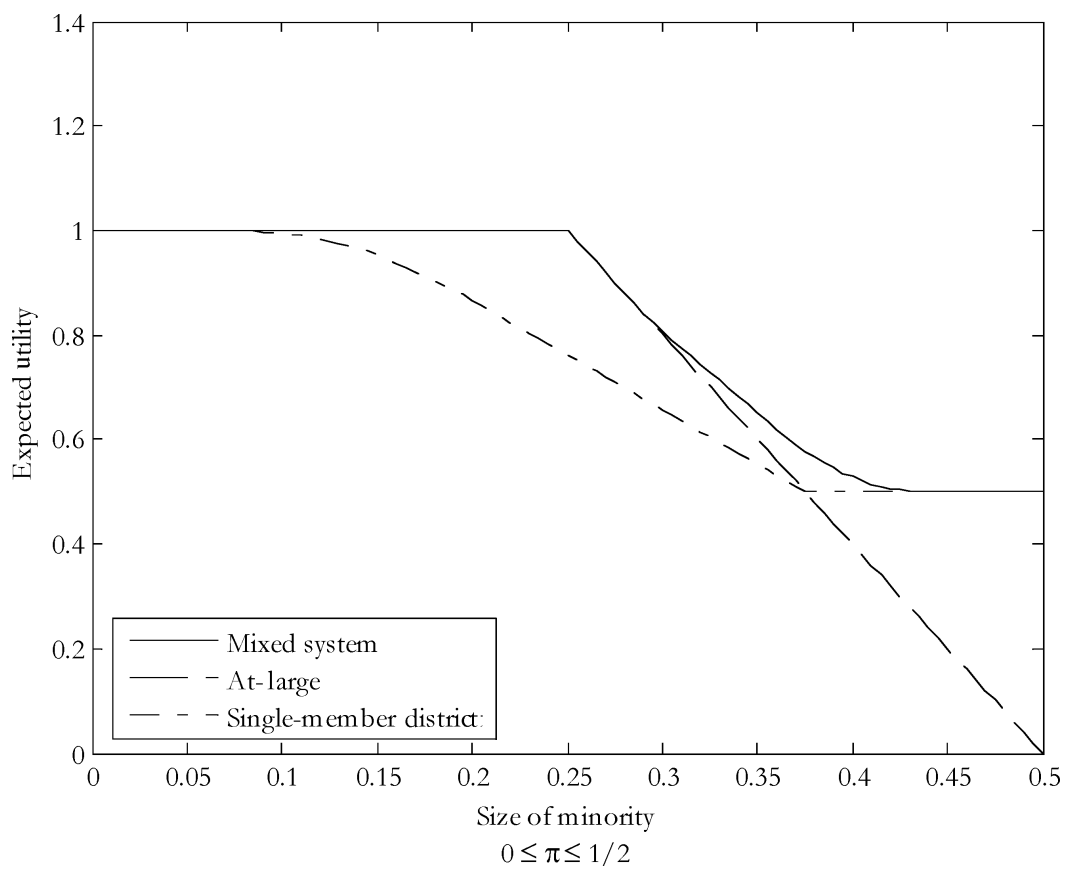

FIGURE III

Expected Utility under Different Electoral Rules as Function of $\pi$

of the minority for a stylized city of $N=12$ districts with $N_{1}=3$, $\rho=5$, and white voters with quadratic preferences, as generated by the model. The fundamental nonlinearity in the choice of the electoral rule extends to the case of mixed systems (notice the ascending part of the step function that indicates the choice of mixed systems). The parabolic curve (quadratic fit) that approximates the relation between $\pi$ and the ratio of SD seats in the council (indicated as SDshare) is precisely the relation we will investigate empirically in Section IV. Figure III reports the expected utilities for the whites under the different electoral rules at various levels of $\pi$. The mixed system curve traces the combination of SD and AL seats that is optimal (i.e., that has the highest expected utility for the whites) at any given $\pi$. Over the range where this curve does not coincide with either pure SD or pure $\mathrm{AL}$, the chosen electoral rule includes both single-member district and at-large councilmen. 


\section{Institutional SETting AND DATA}

\section{III.A. The Voting Rights Act and Its Implementation}

There was no constitutional protection for voting and electoral participation in the United States before the Civil War. ${ }^{13}$ African American individuals in a state of servitude were granted neither citizenship nor voting rights. After the war, during the Reconstruction (1867-1877), Congress provided such constitutional protection with the ratification of the Fourteenth Amendment in 1868 (conferring citizenship to all persons born or naturalized in the United States) and the Fifteenth Amendment in 1870 (providing that the right of vote should not be denied or abridged on the basis of race, color, or previous status of servitude). It is widely acknowledged that the Reconstruction failed to truly enfranchise black voters in the South, whose representation in fact went steadily down from the 1870 s to the 1960 s due to various de facto obstacles to their registration. This does not mean, of course, that no black person would vote, but the share of black voters was quite small. In 1868 there were 300 blacks elected to state legislatures from confederate states; in 1900 there were 5. ${ }^{14}$ The Progressive era (1900-1917) fostered substantial institutional innovations in the direction of reducing representation of minorities. At-large elections were widely introduced both in the South and in the North with the purported scope of curbing corruption and log-rolling between localized factional interests, historically represented by $\mathrm{SD}$, but de facto aiming at reducing the influence of immigrants and (the very few) black voters.

President Lyndon Johnson ratified the 24th Amendment to the Constitution ${ }^{15}$ (1964) and signed into law both the Civil Rights Act in 1964 and the Voting Rights Act in 1965. LBJ relied on a coalition of Northern democrats and republicans to pass the act against the opposition of Southern democrats. The goal of the VRA was (and is) to remove obstacles in voting registration procedures for racial minorities. Section 2 of the Act included a broad

13. We refer to the United States Department of Justice, Civil Rights Division, Voting Section, for further details and references for this section.

14. See in particular the discussion in Kousser (1999) and Grofman and Davidson (1992).

15. The amendment outlawed the poll tax in federal elections. Virginia ratified the amendment in 1977, albeit the ratification process was completed on January 23,1964 (by 38 states). The amendment was ratified by North Carolina in 1989 . The amendment was rejected by the state of Mississippi (and not subsequently ratified) in 1962 . 
reassessment of the principles embedded in the Fourteenth and Fifteenth Amendments. It deemed illegal the use of poll taxes, literacy tests, and the requirement of fluency in English for voting eligibility. As a consequence of the Voting Rights Act, the number of registered minority voters as a fraction of voting age population doubled and in some cases tripled in Alabama, Georgia, Louisiana, Mississippi, and Virginia between 1965 and 1988 (Grofman, Handley, and Niemi 1992). ${ }^{16}$ Even though white Southerners grudgingly had to remove obstacles to black registration (the penalty was jail), they immediately started trying to change electoral laws to minimize the probability of electing black representatives. For instance, already in January 1966, an all-white legislature in Mississippi, without much discussion and unanimously, passed thirteen bills concerning the election process, most of them moving various types of elections to an at-large system. ${ }^{17}$ The purpose was clearly to dilute black votes. Eventually in 1969, in Allen v. State Board of Election, the Supreme Court struck down most of these bills. In fact, the mid-sixties mark the beginning of a long series of court battles about vote diluting, gerrymandering, and various other maneuvers of the white majority to minimize black influence. Different lower courts ruled in different ways and there was much uncertainty about how each specific ruling would go, given the complexity of the issues involved. ${ }^{18}$ Because of all these disagreements in the lower courts, the Supreme Court in 1980 took on the case of City of Mobile $v$. Bolden and established the need to prove discriminatory purposes when challenging a change in electoral rules. ${ }^{19}$ The language of the majority opinion

16. Amy (2002) reports that "the number of black elected officials in the United States grew an average 16.7 percent a year between 1970 and 1977, from 1469 to 4311 " (p. 129). In 1999, according to the Joint Center for Political and Economic Studies, the total number of black elected officials was 5,938 in the South (respectively 8,936 in all states), of which 340 were city mayors (resp. 450 nationwide), 2,677 members of municipal governing bodies (resp. 3,498 nationwide). There were no black senators in 1999 and 19 representatives from the South (39 black representatives nationwide). See also Cole (1976).

17. See the detailed discussion by Parker (1990).

18. For a revealing review of extremely different point of views held by opposing expert witnesses in the cases, see Grofman, Handley, and Niemi (1992) in Grofman and Davidson (1992).

19. In 1980 the Supreme Court imposed the requirement of proof of "racial discriminatory purpose" in vote dilution cases (Mobile v. Bolden, 446 U.S. 55, 1980). This was rectified by a 1982 Congressional amendment dispensing with such proof. The Supreme Court substantially challenged "affirmative gerrymandering" in Shaw v. Reno, 509 U.S. 630 (1993) and Holden v. Hall, 512 U.S. 874 (1994), among others. Under President Bill Clinton, the National Voter Registration Act (also known popularly as the Motor Voter Act of 1993) aimed at strongly promoting voter registration (for example, through the Department of Motor Vehicles structures, 
suggested a very high standard of proof for active discrimination. ${ }^{20}$ In a reaction to this ruling, a 1982 Congressional amendment dispensed with such proof. Finally, in 1986, in the ruling of Thornbourg $v$. Gingles, the Supreme Court clarified what had to be considered active discrimination in a series of points, including the presence of block voting, a history of racial discrimination, evidence of vote diluting, and gerrymandering. Although the court did clarify the issue, still a very large grey area persisted. For instance, as our model itself suggests, the fact that moving to at-large election may dilute black votes, but sometimes moving to single-member districts may disadvantage blacks as well, was already in the minds of litigants in the seventies, eighties, and nineties (see Chapter 5 of Grofman, Handley, and Niemi [1992]). Also, it was not clear how many of the points were necessary and/or sufficient to prove discrimination. This is not a failure of the Court per se, but just reflects the complexity of the issues at hand.

From this brief historical excursus, we need to remember three points germane to our empirical analysis: (1) Until the midsixties white majorities did not have to worry about black votes in the South; only with the Voting Act of 1965 were blacks really a political block to reckon with electorally. (2) The implementation by the courts of the Voting Rights Act also took up the issues of the choice of electoral rules, precisely to avoid choices (such as at-large elections) that would have favored the white majority. (3) Attempts of the white majority to change electoral laws were kept in check by the courts, which became increasingly concerned. But at least well into the eighties and even beyond that, much uncertainty remained about what could or could not be challenged in courts. So a fair amount of room for maneuvering remained for the white majority to strategically manipulate electoral rules. In a sense, without court interventions, our finding below would be even stronger, because the white majority could have acted unconstrainedly.

\section{III.B. Data and Summary Statistics}

This section briefly reviews the main variables employed in the empirical analysis. We refer the reader to the separate Data

unemployment, and welfare bureaus). More recently, the Help America Vote Act of 2001 has shifted back to individual states most of the supervisory power over the quality of electoral franchise. Voting Rights Acts renewal hearings are due in 2007.

20. See Grofman, Handley, and Niemi (1992). 
Appendix ${ }^{21}$ for details on variables definition, construction, and sources. We gathered two sets of data: one including characteristics of city governments and their institutional details; the other including demographic, economic, and geographic characteristics of U.S. cities. We collected information on U.S. municipal government characteristics for the period 1930-2000, at ten-year intervals, from the Form of Government Survey and Municipal Year Book by the International City/County Management Association (ICMA) in Washington, DC. ${ }^{22}$

From the various issues of the ICMA surveys, ${ }^{23}$ we collected information on electoral rules and forms of government for each municipality, including council size; number of district-awarded council seats; and number of councilmen belonging to different racial groups currently sitting in the council. We constructed a single-district variable SDshare, a continuous variable defined as the fraction of councilmen elected in single districts. In 2001 about $65.9 \%$ of the cities in the sample presented only at-largeelected councilmen; about $14.8 \%$ presented only district-elected councilmen. The remaining cities had some combination of the two types of rules (mixed), with councils consisting of a fraction of councilmen representing specific geographic areas and the others "representing the whole city."

From the decade issues of the Bureau of the Census of Population we collected information on total population, racial groups sizes, median household income, and geographic characteristics of places and minor civil divisions (MCDs). ${ }^{24}$ With regard to racial composition, from 1930 to 1970 the data available allow a breakdown into three groups: white, black, and other races (we did not distinguish between foreign-born and native). From 1980 the Census allows a more refined racial breakdown. ${ }^{25}$ Because our empirical analysis runs from the thirties to the nineties, for consistency

21. Due to space limitations we produce the Data Appendix in a separate document, available on request. Please refer to the authors' Web pages for a downloadable version of the Data Appendix.

22. The ICMA is a professional organization of city managers and administrators publishing local government data since 1914 and a recognized scholarly source. ICMA data have been employed in a number of papers, including Baqir (2002), Sass and Pittman (2000), and DeSantis and Renner (1992), among others.

23. Data from 1980 onward are available in electronic format; data before 1980 needed to be collected and entered from hard copies. For this reason we decided to collect data before 1960 only for the South, because it was in the South that the effect of the Voting Rights Act was more relevant and should show larger differences before and after the mid-1960s.

24. Definitions and references in the Data Appendix.

25. In general the breakdown includes at least whites, blacks, Hispanics, Asians, Pacific Islanders, and Native Americans. 
we used the three-groups breakdown (white, blacks, others) for the entire sample. Our variable of interest is the size of nonwhites.

A final caveat: ICMA surveys present different coverage depending on the year. We review their representativeness in terms of population characteristics vis-à-vis the corresponding entire U.S. Census of Population places and MCDs in the Data Appendix. The bottom line is that the sample of U.S. cities collected by ICMA is representative of the total population of relatively large cities, above 2,500 inhabitants, and less representative of the full population of the Bureau of the Census places and minor civil divisions (MCDs). This is why in what follows we always report results for cities above the threshold of $2,500 .{ }^{26}$ In the Appendix Tables A.1 and A.2 we report summary statistics for the key variables of interest for the sample of all U.S. cities and for the sample of Southern cities.

\section{EMPIRICAL RESUltS}

We now focus on the main prediction of our model, namely that the preference of whites for at-large rules over single-member district increases and then decreases with the initial size of the minority group. This section reports four results. First, we present cross-sectional and panel evidence of our main prediction for U.S. cities during the entire period after the enfranchisement of minority voters (the VRA). Second, we show the absence of a relationship between at-large and single-member district rules and the initial size of the minority group during the entire period before the VRA in the South. Third, we focus on the changes taking place around the VRA (immediately before and after the treatment). Fourth, we consider the evidence that an effect of electoral rules on minority representation is present and operates according to the intuition of the model.

\section{IV.A. The Choice of Electoral Rules}

Empirical Strategy. The empirical strategy in Table I and in the majority of the following tables is a simple, yet flexible, linear (in the coefficients) parametric model of the choice of electoral rules. For each city $i$ in year $t$ let us define the electoral rule

26. We were also able to obtain the full lists of cities sampled from the ICMA for the last survey in year 2001 and we verify the absence of any response selection in the survey; see the Data Appendix. 


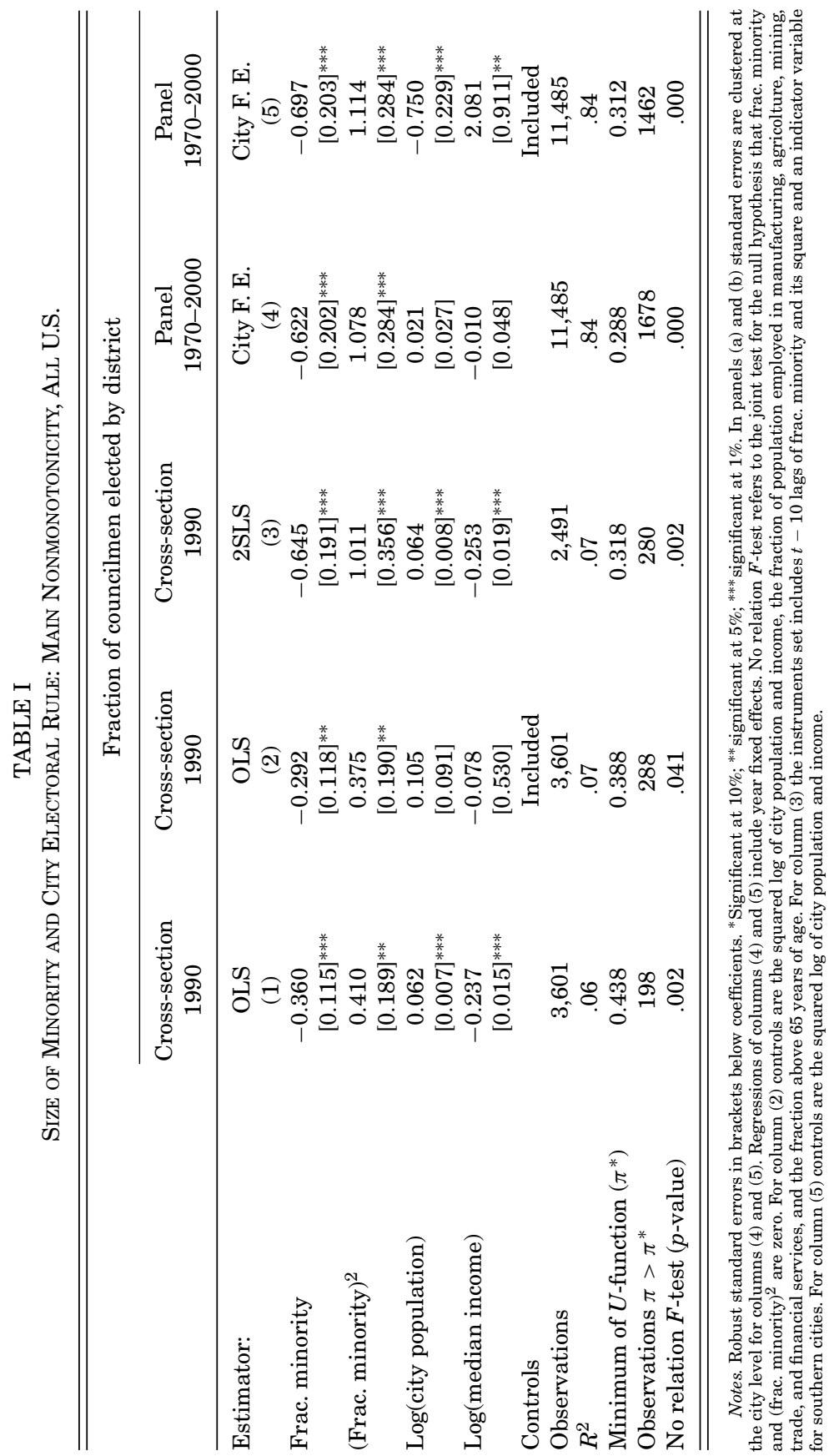


variable, $\mathrm{SDshare}_{i t}$, the relative size of the nonwhite minority, $\pi_{i t}$, a vector of $(k \times 1)$ controls, $X_{i t}$, in our baseline specification: the log of city population and median household income. We specify the following equation in levels:

$$
\begin{aligned}
\text { SDshare }_{i t} & =\beta_{0}+\pi_{i t} \beta_{1}+\left(\pi_{i t}\right)^{2} \beta_{2}+X_{i t}^{\prime} \gamma+u_{i t} \\
\text { for } i & =1, \ldots, N \text { and } t=1, \ldots, T .
\end{aligned}
$$

We perform our analysis both in a cross-section for given $t$ and in a two-way panel in which we account for unobserved, timeinvariant heterogeneity at the city level and for time-specific effects. ${ }^{27}$ In the latter case we assume a two-way error component $u_{i t}=\alpha_{i}+\delta_{t}+\eta_{i t}$. Employing within-city variation allows us to account for unobserved heterogeneity and estimate consistently the vector $\beta=\left(\beta_{1}, \beta_{2}\right)$. Time-specific effects are similarly useful in accounting for across-the-board effects, such as federal legislation, that again need to be controlled for, especially in the post-1965 period when legislation was extremely active. We address the issue of serial correlation in the error component $\eta$ by relaxing the assumption of independence and clustering at the city level. Conditional heteroscedasticity of unknown type is also accounted for in all standard errors both in the cross-section and the panel results.

Identification. The most likely source of reverse causation affecting (2) is endogenous sorting across municipalities driven by more favorable electoral rules. However, Tiebout sorting would predict a correlation between changes in city racial composition and in electoral rules of the opposite sign to that predicted by our model, dampening the least-squares estimates toward zero.

To see this, suppose that, given a small size of the minority, $\pi$, a city changes its electoral rule in favor of white voters against black voters by decreasing the number of single-district seats on the council. In this case Tiebout sorting would predict a decrease in the size of the minority (blacks would leave the city and possibly more whites could join in), implying a positive correlation between the share of single-district seats and the size of the minority at small $\pi$. Now suppose that, given a large size of the minority, $\pi$, a city changes its electoral rule by increasing the number of single-district seats on the council. Under the basic setup of Proposition 1, this produces an unambiguous reduction

27. Formal $F$-tests for this specification support the use of a two-way setup. Both groups of fixed effects are jointly significant in every specification. 
of the expected utility of the blacks. Tiebout sorting would predict a decrease in the size of the minority (blacks would leave the city and possibly more whites would join in), implying a negative correlation between the share of single-district seats and the size of the minority at large $\pi$. However, it is enough to move to our more general theoretical setup, including risk aversion, to see that moving toward single-member districts at high $\pi$ may produce an increase in the utility of both groups. In this case Tiebout sorting could produce an overestimate of the true slope of the $U$-curve in the rightmost range of $\pi$. We address this potential endogeneity by instrumenting the fraction of the minority with ten-year lags and geographic location (an indicator variable taking value 1 if the city is in the South). Distant lags and geographic location should be considered predetermined or exogenous (the case for the South) and therefore valid instruments of the current size of the minority. Exclusion restrictions can be tested given overidentification of the system.

Results. Table I presents the results concerning the main nonmonotonicity. The table refers to the sample of U.S. $\operatorname{cities}^{28}$ in 1990 for the cross-sectional analysis (in columns (1)-(3)) and to the period 1970-2000 for the panel analysis (columns (4) and (5)). The model calls for a negative linear and a positive quadratic coefficient on the share of the nonwhite minority. ${ }^{29}$ The signs of the coefficients are consistent with this story and significant at standard confidence levels both individually and jointly. Looking at column (1), the estimated coefficients imply that the $U$-shaped curve reaches a minimum (indicated with $\pi^{*}$ ) at about $43.8 \%$ nonwhite minority. (Note that $94.5 \%$ of the cities in the year 1990 were below this level.) In column (2) we include for robustness a larger set of controls, of which we do not report the coefficients. For column (2) the controls are the squared log of city population and income, the fraction of population employed in manufacturing,

28. As for all the rest of our empirical analysis, we exclude from the sample those cities for which we have information that the change of structure of government is the result of court mandate or state law. We also exclude cities below 2,500, as the ICMA sample is representative of the U.S. Census of Population places and MCDs in this group. Similar results were obtained when employing the complete sample of municipalities or performing the cross-sectional analysis for the years 1980 and 2000.

29. Note that one may want to exclude cities in which whites are a minority. There are very few of these, and in addition, even when whites are a minority in terms of number of inhabitants, demographic factors and voting participation patterns may still make them a majority as active voters (see Amy [2002] for an example). For this reason it is unclear which cities to drop from the sample. We tried a few experiments and our results appear robust. 
agriculture, mining, trade, and financial services, and the fraction above 65 years of age. The estimated coefficients support qualitatively the results of column (1), with a lower minimum at 0.388 , and are again individually and jointly significant.

Column (3) reports 2SLS estimates of the specification in column (1). Consistent with our previous discussion concerning identification, the coefficients on the linear and quadratic terms become larger in absolute value and outside the $95 \%$ confidence interval for the estimates of column (1). This finding seems to suggest a reduction of the possible attenuation bias stemming from Tiebout sorting. A $J$-test for overidentification of all instruments produces a $p$-value of .12, thus not rejecting the validity of the instruments set in terms of exclusion restrictions. It is a low value, however, given the low power properties of the test. The minimum for the $U$-shaped curve is estimated at 0.318 minority size.

In columns (4) and (5) we tackle the issue of unobserved heterogeneity at the city level in our baseline specification and in one where additional controls are added. For column (5), controls are the squared log of city population and median income. We obtain estimates of $\beta=\left(\beta_{1}, \beta_{2}\right)$ close to the 2SLS estimates and statistically significant at the $1 \%$ confidence level (both individually and jointly).

To gauge quantitatively the size of the two effects in Table I, we can start from the empirical distribution of minorities in U.S. cities in the year 1990 for the cities in our sample. ${ }^{30}$ The median (Q5) for the fraction of minority is $5.5 \%$ and the ninth decile (Q9) is $34.3 \%$. At Q5, given estimated coefficients in column (4) of -0.622 and 1.078 (with robust standard errors respectively 0.202 and 0.284 ), an increase of one standard deviation of minority sizes $(15.3 \%)$ implies a reduction of $-5.3 \%$ of the fraction of single-district seats. This is equivalent to about one-third seat switching from single-member district to at-large in a council of six seats (the mean council size in the 1990 sample). At Q9, the same increase of one standard deviation would instead produce an increase of about $+4.4 \%$ in the fraction of single-district seats. This would be equivalent to more than one-fourth seat switching from at-large to single-district in a council of six seats. The estimates are quantitatively reasonable, since the voting rights legislation over the years has imposed increasing limits on institutional changes.

30. But likewise for the decades 1980, 2000. 
We also separately run a battery of robustness checks that we do not report for parsimony of presentation First, we have considered a discrete version of our dependent variable, SD, and found analogous evidence of the main nonmonotonicity for both the cross section and the panel (using conditional logit fixed effects). Similarly, we have considered a (two-sided) limited dependent variable (LDV) approach: a Tobit and IV Tobit estimator for columns (1)-(3) and a random effects Tobit estimator grouping observations at the city level for columns (4) and (5). This is a way of incorporating the empirical feature that SDshare is constrained to be in $[0,1]$. The implications of Table I carry over to the LDV specification consistently with the predictions of Proposition 1. Second, because time dependence is an important characteristic of political systems, we have included the $t-10$ lag of SDshare and employed a standard dynamic panel technique, through first differencing and application of the Arellano and Bond (1991) GMM estimator. The consistency of the standard linear model and this dynamic extension are sources of reassurance. The dynamic model delivers larger effects, in the range of one-half seat in a council of six (toward and away from AL), especially for the South. Third, we have also considered a simple nonparametric approach, expecting to observe two basic regularities in the data: (1) the slope of a within-city regression of the single-district variable on the fraction of the minority should be increasing in subsamples where the average minority size is increasingly higher; (2) we would expect statistically significant coefficients of negative sign to appear at relatively small values of the fraction of the minority (the steeper downward-bending part of the U) and statistically significant coefficients of positive sign to appear at relatively large values of the fraction of the minority (the steeper upward-bending part of the U). A flat and insignificant relationship should appear in the middle range. Both regularities seem supported by the data. Fourth, as additional nonparametric evidence, we have estimated the cross-sectional regression of Table I using dummies by quintile of the minority population. The coefficients on the dummies first decrease and then increase (at the fifth quintile) as expected (however, only the decreasing portion of the $U$ curve produces statistically significant contrasts).

\section{IV.B. Before the VRA}

An important validation issue in the empirical strategy concerns the timing of the Voting Rights Act. We employ such data as an informative source of variation for institutional manipulation. 
TABLE II

PRe-VRA in the South: Validation Tests

\begin{tabular}{lccc}
\hline \hline & \multicolumn{2}{c}{ Fraction of councilmen elected by district } \\
\cline { 2 - 4 } & Cross-section & Cross-section & Panel \\
& 1950 & 1960 & $1930-1960$ \\
\hline Estimator: & OLS & OLS & City F. E. \\
& $(1)$ & $(2)$ & $(3)$ \\
Frac. minority & 0.308 & 0.226 & 0.406 \\
& {$[0.413]$} & {$[0.358]$} & {$[0.841]$} \\
Frac. minority $)^{2}$ & -0.852 & -0.478 & -0.661 \\
& {$[0.776]$} & {$[0.744]$} & {$[1.322]$} \\
Log(city population) & -0.045 & -0.015 & 0.001 \\
& {$[0.021]^{* *}$} & {$[0.017]$} & {$[0.042]$} \\
Log(median income) & & -0.145 & \\
& & {$[0.058]^{* *}$} & \\
Observations & 486 & 652 & .482 \\
$R^{2}$ & .01 & .02 & .882 \\
No relation $F$-test & .376 & .811 & \\
$\quad(p$-value) & & & .81 \\
\hline \hline
\end{tabular}

Notes. Robust standard errors in brackets below coefficients. ${ }^{*}$ Significant at $10 \%$; ${ }^{* *}$ significant at $5 \%$; *** significant at $1 \%$. In panels (a) and (b) standard errors are clustered at the city level for column (3). Regressions of column (3) include year fixed effects. No relation $F$-test refers to the joint test for the null hypothesis that (frac. minority) and (frac. minority) ${ }^{2}$ are zero.

Table II reproposes the specifications of columns (1) and (4) of Table I before the Voting Rights Act of 1965. The sample covers Southern cities before the VRA. Column (1) refers to the 1950 cross section, ${ }^{31}$ column (2) to the 1960 cross section, and the panel analysis covers the period 1930-1960. Here the coefficients on the size of the minority and its square are statistically zero. Joint $F$-tests for the linear and quadratic terms of minority size present high $p$-values (.376 for column (1) in Panel A) and the coefficients display changes of sign. This is consistent with our hypothesis that before the Voting Act electoral rules were unaffected by the city racial composition, because racial minorities were almost completely disenfranchised.

\section{IV.C. The VRA}

In this section we try to identify the effect of the extension of the electoral franchise in the immediate aftermath of the VRA on

31. Median household income is not available before 1960; hence it is not included in specifications covering those years. 
the choice of electoral rules from the subsequent legal restrictions imposed on the choice of the electoral rules. A way of addressing this issue is to make appropriate use of the timing of the voting rights lawsuits and Supreme Court jurisprudence. Accordingly, Table III focuses on the period around the VRA but before the Supreme Court decision ${ }^{32}$ of 1969 (the early post-VRA sample). Our approach is to take the percent minority in 1960 and use it to predict the change in institutions between 1960 and 1967 (the closest ICMA survey available) in southern cities, the ones more directly affected by the VRA. The drawback of focusing solely on the immediate post-VRA sample, however, is that only partial registration of the minorities had been accomplished before 1967 and full enfranchisement even of large minority groups was still uncertain and surely incomplete. We estimate the following specification:

$$
\begin{aligned}
& \Delta \text { SDshare }_{i, 1960-1967}=\pi_{i, 1960} \beta_{1} \\
& \quad+\left(\pi_{i, 1960}\right)^{2} \beta_{2}+\Delta X_{i 1960-1967}^{\prime} \gamma+\Delta u_{i 1960-1967 .}
\end{aligned}
$$

The coefficients $\beta=\left(\beta_{1}, \beta_{2}\right)$ can be interpreted as a measure of the effect of an increase in the relative size of racial minorities in the South on the electoral rules.

Estimates $^{33}$ of the gap between fractions of white and black registered voters decreased from $44.1 \%$ to $27.4 \%$ from 1965 to 1967, but with half the black population still disenfranchised. In a city with $50 \%$ blacks in 1967 only $25 \%$ were voting, leaving whites $^{34} 1.6$ to 1 . This means that our analysis will be particularly apt at capturing the effects at low $\pi$.

Table III presents the results. In the upper part of Table III we first report tabulations of all the within-city changes in electoral rules that identify (3). By splitting the sample by electoral rule in 1960 we are able to detect two relevant facts: (i) in 1960 the majority of the cites in the South were AL (SDshare $<.5$ ), a remnant of the Progressive era; (ii) the bulk of the changes happened in cities where SDshare $>.5$. Basically all Southern cities employing an AL rule kept it unchanged at the moment of the black enfranchisement, and a vast majority of the SD cities moved toward at-large in a way consistent with intuition and our model. If a city moves from

32. Allen v. State Board of Election.

33. See Grofman, Handley, and Niemi (1992, p. 23).

34. Assuming an average white registration rate around $80 \%$ (see Grofman, Handley, and Niemi [1992, p. 23]). 


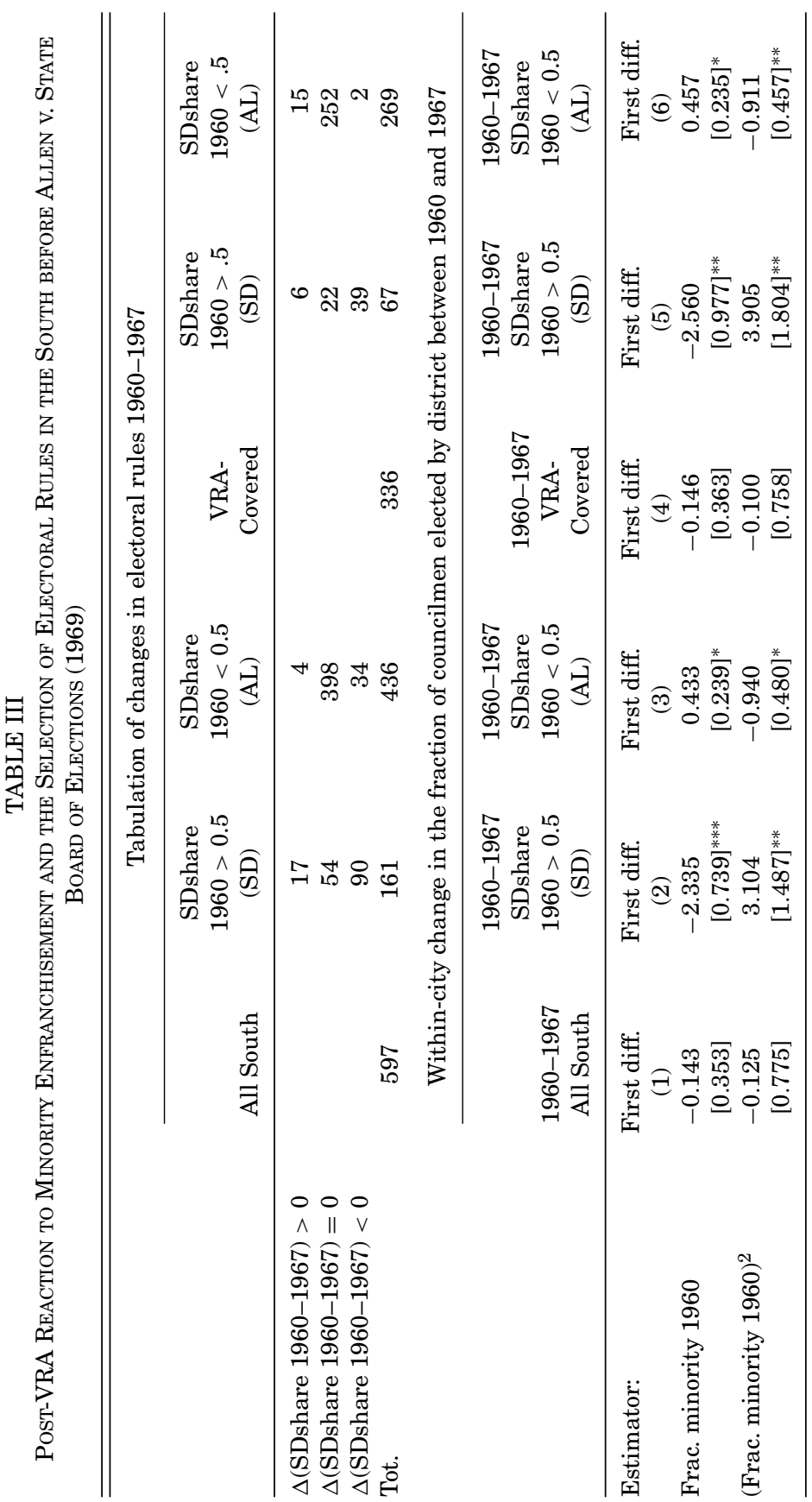




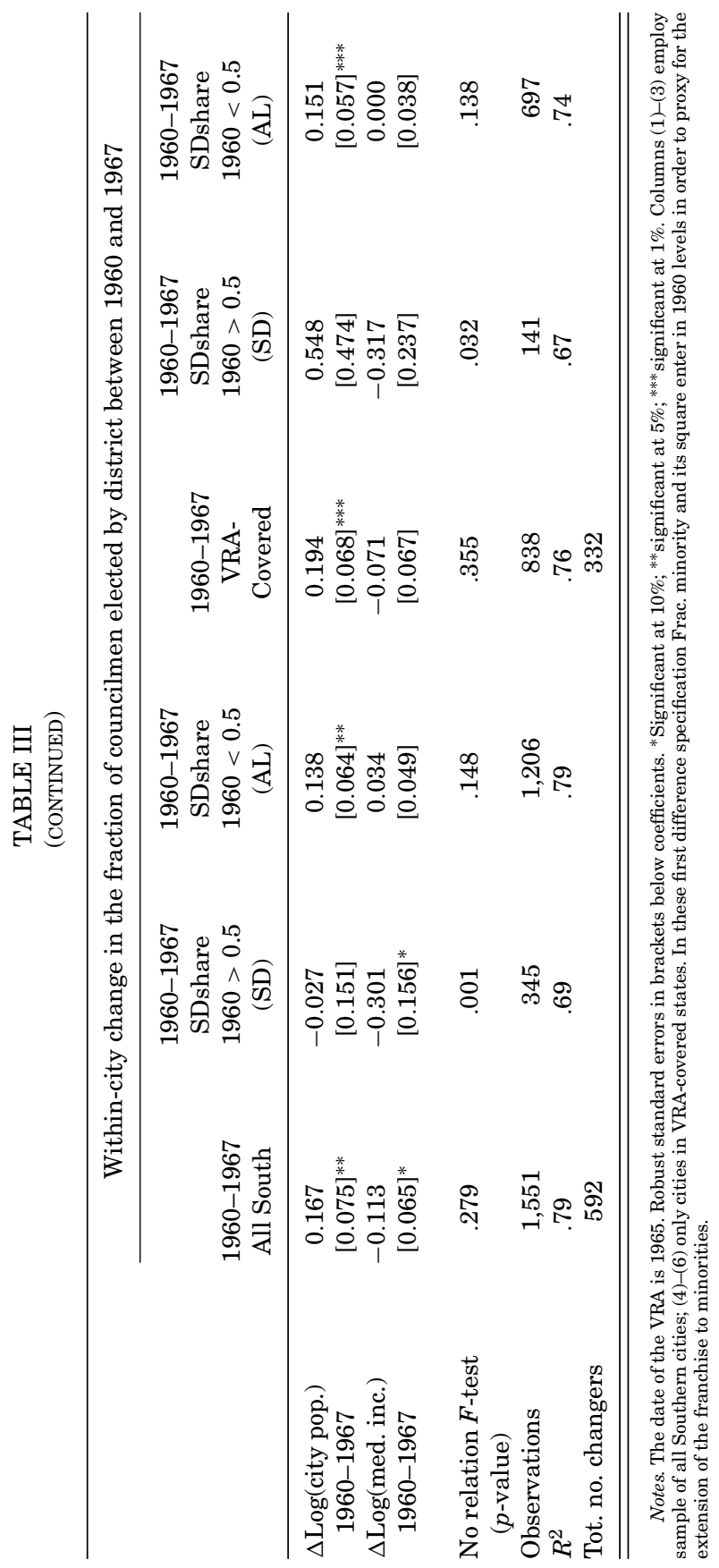


zero voting minority (where the electoral rule is inconsequential) to $\pi<\pi^{*}$, the only type of city that should change is the (initially) SD moving toward AL. The AL cities should not move unless $\pi$ is very large. It is therefore not surprising that our results will be especially strong concerning the movement toward AL.

Column (1) in the bottom part of Table III presents firstdifference estimates for the specification (3), where the fraction of the minority enters linearly at the 1960 level and in a quadratic form. The estimated coefficient $\beta_{1}$ presents the expected sign but not $\beta_{2}$, and both are not statistically significant. In column (2) we run the same regression in the portion of the data containing the identifying information: the initially SD cities. Importantly, the regression picks up both the linear and the quadratic effects in a way consistent with the theory. Similar to Section IV.A, we can calculate the effect of an increase of one standard deviation of minority sizes (0.153). The effects are $-23.2 \%$ (at Q5) and $+4.1 \%$ (at Q9) of the share of single-member seats. The negative effect is around four times larger than in Table I, confirming substantial pressure toward endogenous changes in the electoral rules. In column (3) we restrict to the set of initially AL cities. Here identification is due to a very small fraction of cities, the few changing, and we find a counterintuitive swap in coefficient signs and borderline significance for the $t$-tests. Notice, however, that these findings are countervailed by lack of joint significance of the coefficients on $\pi$ and $\pi^{2}$, a result consistent with the model. Reassuringly, the $F$-test $p$ value does not warrant rejection at any standard confidence level.

It is also relevant to investigate how our results would change depending on the VRA coverage. In columns (4)-(6) we run the same specifications as for columns (1)-(3) on the VRA-fully covered states, with stronger results than in the overall South sample. Estimates especially differ on the quantitative implications for the increasing part. Repeating our calculations, the two estimated effects are now $-23.5 \%$ at Q5 and $+11 \%$ at Q9 for the sample of cities initially SD. Again we detect individual but no joint significance of $\pi$ and $\pi^{2}$ for the $\mathrm{AL}$ cities (the $F$-test $p$-value does not warrant rejection at any standard confidence level).

\section{IV.D. Minority Representation}

Our basic story holds that electoral rules affect the ratio of minorities elected differently. The representational ratio $(\mathrm{RR})$ is the fraction of minority councilmen in a council divided by the fraction of the population that belongs to the minority and is available 
TABLE IV

City Electoral Rule and MinoRity Representation: Cross-SeCtional and WITHIN-CITY VARIATION

\begin{tabular}{|c|c|c|c|c|}
\hline Sample: & All U.S. & $\begin{array}{c}\text { Frac. minority < } \\
\text { mean(frac. } \\
\text { minority) }\end{array}$ & $\begin{array}{c}\operatorname{mean}(\text { frac. } \\
\text { minority })<\text { frac. } \\
\text { minority }<\pi^{*}\end{array}$ & $\begin{array}{l}\pi^{*}<\text { frac. } \\
\text { minority }\end{array}$ \\
\hline & $\begin{array}{r}\text { Pan } \\
\text { Depende }\end{array}$ & $\begin{array}{l}\text { el A: OLS, cross-se } \\
\text { nt variable: repres }\end{array}$ & $\begin{array}{l}\text { ction } 1990 \\
\text { sentaional ratio }\end{array}$ & \\
\hline & (1) & (2) & (3) & (4) \\
\hline \multirow[t]{2}{*}{ SD share } & 0.082 & 0.081 & 0.146 & 0.088 \\
\hline & {$[0.031]^{* * *}$} & {$[0.038]^{* *}$} & {$[0.057]^{* *}$} & [0.059] \\
\hline \multirow[t]{2}{*}{ Log(city population) } & 0.072 & 0.036 & 0.051 & 0.053 \\
\hline & {$[0.011]^{* * *}$} & {$[0.018]^{* *}$} & {$[0.017]^{* * *}$} & {$[0.021]^{* *}$} \\
\hline \multirow[t]{2}{*}{ Log(median income) } & -0.208 & -0.092 & -0.507 & -0.202 \\
\hline & {$[0.033]^{* * *}$} & {$[0.035]^{* * *}$} & {$[0.081]^{* * *}$} & {$[0.073]^{* * *}$} \\
\hline \multirow[t]{2}{*}{ Frac. minority } & 1.127 & 3.821 & 0.156 & 0.833 \\
\hline & {$[0.057]^{* * *}$} & {$[0.426]^{* * *}$} & [0.239] & {$[0.177]^{* * *}$} \\
\hline Observations & 3,507 & 2,375 & 934 & 198 \\
\hline \multirow[t]{4}{*}{$R^{2}$} & .13 & .06 & .10 & .13 \\
\hline & Panel B: & city fixed effects, $p$ & anel 1980-2000 & \\
\hline & Depende & nt variable: repres & entaional ratio & \\
\hline & (1) & (2) & (3) & (4) \\
\hline \multirow[t]{2}{*}{ SD share } & 0.216 & 0.027 & 0.433 & 0.296 \\
\hline & {$[0.058]^{* * *}$} & [0.102] & {$[0.193]^{* *}$} & {$[0.092]^{* * *}$} \\
\hline \multirow[t]{2}{*}{ Log(city population) } & 0.087 & 0.188 & -0.131 & -0.028 \\
\hline & {$[0.080]$} & {$[0.115]$} & {$[0.288]$} & [0.132] \\
\hline \multirow[t]{2}{*}{ Log(median income) } & -0.017 & -0.043 & 0.269 & -0.163 \\
\hline & {$[0.120]$} & {$[0.150]$} & {$[0.518]$} & [0.264] \\
\hline \multirow[t]{2}{*}{ Frac. minority } & -0.248 & -0.359 & -0.858 & -0.272 \\
\hline & {$[0.227]$} & [1.105] & [1.678] & {$[0.472]$} \\
\hline Observations & 10,252 & 6,874 & 1,925 & 1,453 \\
\hline$R^{2}$ & .71 & .67 & .87 & .87 \\
\hline
\end{tabular}

Notes. Robust standard errors are in brackets below coefficients. * Significant at $10 \%$; ** significant at $5 \%$; *** significant at $1 \%$. Standard errors are clustered at the city level in Panel B. In Panel B all regressions include year fixed effects and sample coverage period is $1980-2000$. The representational ratio is the fraction of nonwhite councilmen in the council divided by the fraction of the population that is nonwhite.

for our all-U.S.-cities sample in the years 1980, 1990, and $2000 .^{35}$ We regress $R R$ on our variable of interest, the single-district rule variable. Table IV reports the results. The null hypothesis

35. Very few cities for the all-U.S. sample present representational ratios of minorities of more than 1, indicating overly proportional representation. Even fewer of them are present in the South. In order to limit the role of these outliers, we limit the representational ratio to be smaller than 5 . 
that the electoral rule adopted by a city has no association with the representational ratio is soundly rejected both in a 1990 cross-sectional regression (Panel A, column (1)) and in fixed-effect regressions in which time-invariant city-specific unobserved heterogeneity is accounted for (Panel B, column (1)). ${ }^{36}$ Singledistrict rules substantially increase the chance of minorities to be proportionally represented at the municipal level. Recalling that the fraction of single-district seats, SDshare, is defined over the $[0,1]$ interval, our results in column (1) imply an average increase in the RR of the city council between $8.2 \%$ (in Panel A) and $21.6 \%$ (in Panel B) from switching from a fully at-large rule to a fully single-district rule. This is a quantitatively substantial effect: each black or minority vote has more than one-fifth more weight in terms of electoral representation under single-district than under at-large elections. ${ }^{37}$ Finally, let us note that the correlations presented in column (1) identify the effect of the electoral rule on the representational ratio without the strong exclusion restriction that the fraction of the minority has an independent effect on RR.

In columns (2)-(4) we provide evidence that the impact of the single-district rule on the representational ratio is actually nonmonotonic in the size of the minority by looking at the effect of the single-district variable at different levels of $\pi$. As discussed above, our model implies that the sign of the coefficient should be the highest in intermediate ranges of $\pi$ and the lowest when the fraction of the minority is either very small or very large. The three ranges we employ are below the mean of $\pi ; ;^{38}$ between the mean and the minimum, $\pi^{*}$, of the $U$ computed in Table I (column (1) for the cross-section and (4) for the panel); and above $\pi^{*}$. The effect of single-district is quantitatively always stronger at intermediate ranges. A similar picture arises in the fixed effect analysis of Panel B. Note that the effect of SDshare is consistently significant and large in both the cross section and the panel only at intermediate ranges of $\pi$. The results are influenced by the choice of the thresholds, but the decreasing effect of SDshare seems to be a robust feature of the data.

36. All panel specifications include year fixed effects and a set of standard controls for city size (log population) and income levels (log household median income in 1990 dollars), and we apply the same clustering as in Table I.

37. Focusing on the South produces even stronger estimates, in a range of one-third. Sass and Pittman (2000) also provide panel data evidence on the effect of electoral rule on minority representation reporting a representational ratio differential of $36 \%$ larger then but comparable with our estimates. Our results extend to more recent data and a substantially larger sample of cities.

38 . The mean $\pi$ for the 1990 sample is 0.125 , and that for the panel is 0.130 . 


\section{Conclusions}

This paper studies the problem of minority representation in political systems where majorities can strategically manipulate electoral rules. Empirical validation of this approach comes from the experience of cities in the United States before and after the Voting Rights Act of 1965.

Before the Voting Rights Act, racial minorities were essentially disenfranchised in the U.S. South. Therefore, the type of electoral institutions was irrelevant in determining the level of control of the white majority - a level of control that was almost absolute. The Voting Rights Act allowed racial minorities to enter into the political arena. The white majorities reacted, within the legal boundaries of the Voting Rights Act, by changing electoral rules to minimize expected minority influence. This evidence suggests how institutions (in this case electoral rules) evolve rather quickly in response to changes in the environment and raises questions about empirical evidence that holds electoral institutions as exogenous.

\section{Appendix I: Proofs of Propositions}

Proof of Proposition 1. Part (a) is straightforward. For part (b) consider that

$$
L_{W}^{\mathrm{AL}}=0<L_{W}^{\mathrm{SD}} \text { if } \pi \in\left(\frac{1}{3}-\frac{\bar{\alpha}}{6}, \frac{1}{2}-\frac{\bar{\alpha}}{6}\right) ;
$$

and $L_{W}^{\mathrm{AL}}$ and $L_{W}^{\mathrm{SD}}$ are both linear increasing in $\pi$ for $\pi \in(1 / 2-$ $\bar{\alpha} / 6,1 / 3)$. At $\pi=1 / 3$, we may have two cases. In Case 1 , it holds that

$$
L_{W}^{\mathrm{AL}}=\left(1-\frac{1}{\bar{\alpha}}\right) \Delta>L_{W}^{\mathrm{SD}}=\delta
$$

and hence a unique cut-off $\widehat{\pi} \in(1 / 2-\bar{\alpha} / 6,1 / 3)$ exists with the desired properties. In Case 2,

$$
\Delta\left(1-\frac{1}{\bar{\alpha}}\right) \leq \delta \quad \text { and } \quad \Delta>\delta .
$$

For $\pi \in(1 / 3,1 / 2)$ the loss $L_{W}^{\mathrm{AL}}$ is linear increasing in $\pi$ and $L_{W}^{\mathrm{SD}}$ is constant at $\delta$. Hence the existence of a unique cut-off $\widehat{\pi} \in(1 / 3,1 / 2)$ in this case. Finally, to establish part (c) consider that for any $\pi$ between 0 and $1 / 2$, we have

$$
L_{W}^{\mathrm{SD}} \geq L_{W}^{\mathrm{AL}},
$$


because here $\Delta=\delta$ and

$$
\left(1-\frac{2}{\bar{\alpha}}(1-3 \pi)^{+}\right)^{+} \geq\left(1-\frac{3}{\bar{\alpha}}(1-2 \pi)\right)^{+} .
$$

At $\pi=1 / 2$, (4) holds with equality. This establishes the proposition.

Proof of Proposition 2. Define $N_{1} / N=n_{1}$ and $\rho=N_{\text {Tот }} / N$. Normalize $u(0)=0$. The expected utility of a pure AL is

$$
U_{W}^{\mathrm{AL}}=\operatorname{Pr}(\alpha<X) u(1),
$$

where $X(\pi)=N(1-2 \pi)$.

The probability under a single-member district system of winning type-2 districts $1,2, \ldots, N_{2}$ for $W$ is

$$
\operatorname{Pr}\left(\alpha<\frac{\left(1-2 \pi N / N_{2}\right)}{f}\right) .
$$

With constant $f=1 / N_{2}$ indicate $Y(\pi)=\left(1-2 \pi N / N_{2}\right)^{+} / f=\left(N_{2}-\right.$ $2 \pi N)^{+}$. Then the expected utility of pure SD for given $\pi$ is

$$
U_{W}^{\mathrm{SD}}=\operatorname{Pr}(\alpha>Y) u\left(n_{1}\right)+\operatorname{Pr}(\alpha<Y) u(1) .
$$

Notice that $X(\pi)>Y(\pi), \forall \pi$.

Consider the value of $\pi^{*}$ at which the expected share of seats won by $W$ is the same under pure AL and pure SD. For any $\pi<\pi^{*}$, $\mathrm{AL}$ is actuarially more favorable than SD. If $W$ is risk averse, the $\hat{\pi}$ at which $U_{W}^{\mathrm{SD}}=U_{W}^{\mathrm{AL}}$ lies in the interval $\left(\pi_{0}^{\mathrm{AL}}, \pi^{*}\right)$, since $\mathrm{AL}$ is a riskier electoral rule. A unique point $\hat{\pi}$ always exists, as shown in the text. It follows that

where

$$
\begin{aligned}
U_{W}^{\mathrm{SD}} & =U_{W}^{\mathrm{AL}} \\
& \Longrightarrow \operatorname{Pr}(\alpha>Y)=\operatorname{Pr}(Y<\alpha<X) \frac{u(1)}{u\left(n_{1}\right)},
\end{aligned}
$$

$$
\begin{aligned}
& \operatorname{Pr}(\alpha>Y)=1-\left(N_{2}-2 \pi N\right)^{+} / \bar{\alpha} \\
& \operatorname{Pr}(Y<\alpha<X)=N_{1} / \bar{\alpha} .
\end{aligned}
$$

Hence (5) implies that at $\hat{\pi}$,

$$
\frac{u(1)}{u\left(n_{1}\right)}=\frac{\bar{\alpha}}{N_{1}}-\frac{1}{N_{1}}\left(N_{2}-2 \hat{\pi} N\right)^{+}<\frac{\bar{\alpha}}{N_{1}}<\frac{N}{N_{1}} .
$$

A risk averse $W$ will always accept at least a small amount of risk that is actuarially favorable. Therefore, at $\hat{\pi} W$ will prefer a mixed system to a pure SD rule. 
To see this, define the number of SD councilmen per district $\rho$ and consider the problem of $W$ for $\pi=\hat{\pi}$ :

$$
\max _{\underline{\rho}}\left\{U_{W}^{\mathrm{MX}}(\underline{\rho})\right\}
$$

subject to $0 \leq \rho \leq \rho$.

The expected utility of a mixed system MX for given $\pi$ is

$$
\begin{aligned}
U_{W}^{\mathrm{MX}}= & \operatorname{Pr}(\alpha>X) u\left(\underline{\rho} n_{1} / \rho\right)+\operatorname{Pr}(Y<\alpha<X) u \\
& \times\left(\left(\underline{\rho} n_{1}+\rho-\underline{\rho}\right) / \rho\right)+\operatorname{Pr}(\alpha<Y) u(1) .
\end{aligned}
$$

By using the expression in (7) and allowing $\rho$ to take continuous values, the FOC for the problem is

$$
\begin{aligned}
\Phi(\underline{\rho})= & \frac{1}{\rho}\left[n_{1} \operatorname{Pr}(\alpha>X) u^{\prime}\left(\underline{\rho} n_{1} / \rho\right)\right. \\
& \left.-\left(1-n_{1}\right) \operatorname{Pr}(Y<\alpha<X) u^{\prime}\left(\left(\underline{\rho} n_{1}+\rho-\underline{\rho}\right) / \rho\right)\right] .
\end{aligned}
$$

Consider $\Phi(\underline{\rho})$ at $\pi=\hat{\pi}$,

$$
\begin{aligned}
\Phi(\underline{\rho})= & \frac{\operatorname{Pr}(Y<\alpha<X)}{\rho N} \\
& *\left[N_{1}\left(\frac{u(1)}{u\left(n_{1}\right)}-1\right) u^{\prime}\left(\underline{\rho} n_{1} / \rho\right)-N_{2} u^{\prime}\left(\left(\underline{\rho} n_{1}+\rho-\underline{\rho}\right) / \rho\right)\right],
\end{aligned}
$$

where we use the fact that $\operatorname{Pr}(\alpha>X)=\operatorname{Pr}(\alpha>Y)-\operatorname{Pr}(Y<\alpha<$ $X)$ and condition (5). We are interested in evaluating (8) at $\underline{\rho}=\rho$ :

$$
\Phi(\underline{\rho}=\rho)=\frac{\operatorname{Pr}(Y<\alpha<X)}{\rho N} u^{\prime}\left(n_{1}\right)\left[N_{1}\left(\frac{u(1)}{u\left(n_{1}\right)}-1\right)-N_{2}\right] .
$$

By replacing in (9) the expression in (6) we can see that the FOC is strictly negative at $\rho=\rho$. This is because the element in brackets in (9) is strictly negative by (6):

$$
N_{1} \frac{u(1)}{u\left(n_{1}\right)}-N<0 .
$$

This excludes $W$ choosing a pure SD system. Because at $\hat{\pi} U_{W}^{\mathrm{SD}}$ is not the optimum and $U_{W}^{\mathrm{SD}}=U_{W}^{\mathrm{AL}}$, a pure $\mathrm{AL}$ rule cannot be an optimum either. This implies that $W$ will choose a mixed system with $\rho \neq 0, \rho \neq \rho$. Finally, by continuity, in a neighborhood $\left(\pi_{3}, \pi_{4}\right)$ of $\hat{\pi}$ the same must hold.

This establishes the proposition. 


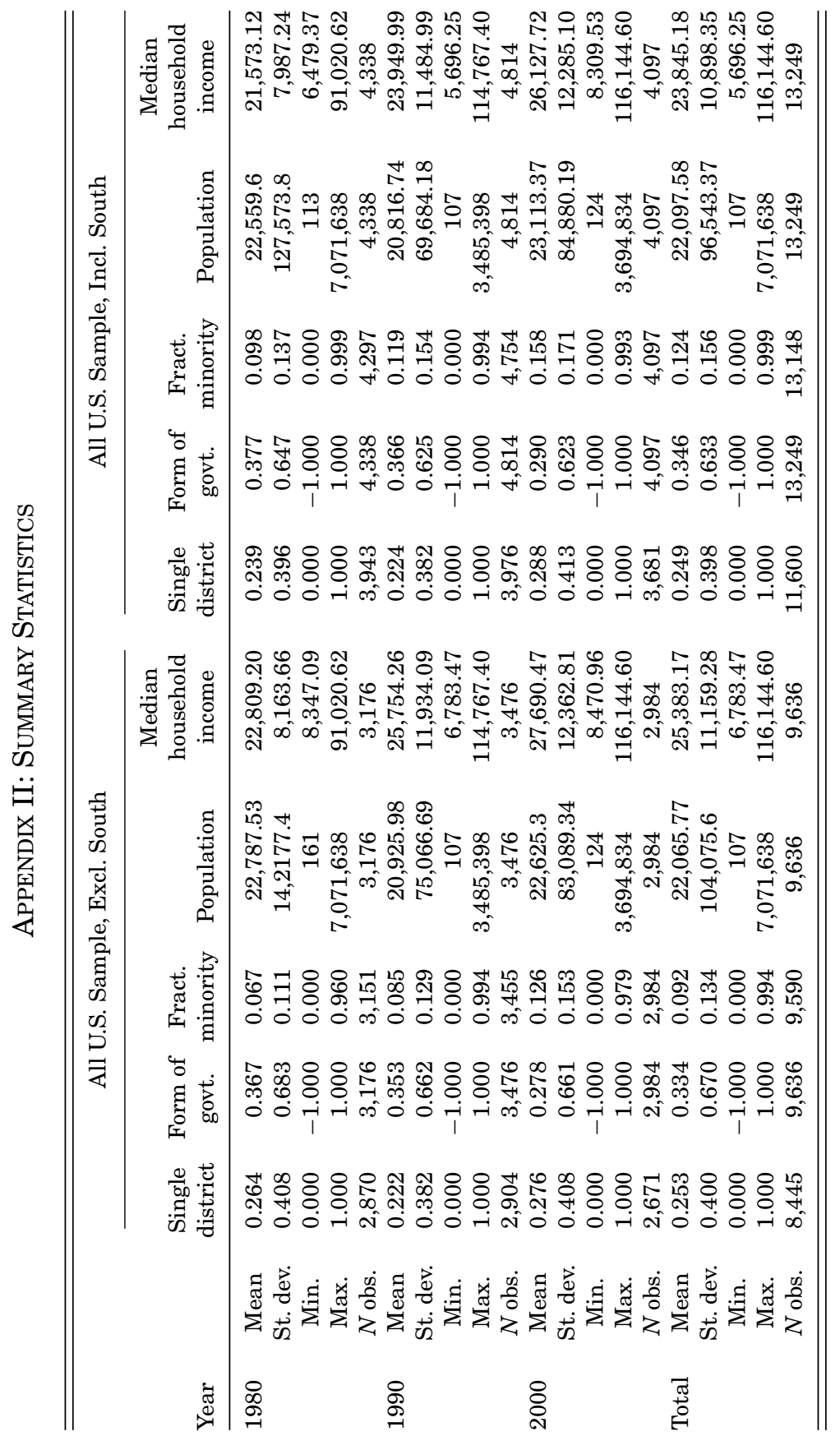


ApPendix III: SUmmary Statistics: South REgion

\begin{tabular}{|c|c|c|c|c|c|}
\hline Year & & Single district & $\begin{array}{l}\text { Form of } \\
\text { government }\end{array}$ & Fract. minority & Population \\
\hline \multirow[t]{5}{*}{1930} & Mean & 0.1901865 & 0.6144578 & 0.240152 & $55,689.73$ \\
\hline & St. dev. & 0.3417885 & 0.6756604 & 0.1527653 & $97,710.1$ \\
\hline & Min. & 0 & -1 & 0.00094 & 284.928 \\
\hline & Max. & 0.9473684 & 1 & 0.9616204 & $80,4874.1$ \\
\hline & $N$ obs. & 144 & 166 & 137 & 137 \\
\hline \multirow[t]{5}{*}{1940} & Mean & 0.3677645 & 0.2313253 & 0.2214527 & $44,127.13$ \\
\hline & St. dev. & 0.4594916 & 0.7952042 & 0.1455125 & $85,805.16$ \\
\hline & Min. & 0 & -1 & 0.0002387 & 4,868 \\
\hline & Max. & 1 & 1 & 0.5976929 & $859,100.3$ \\
\hline & $N$ obs. & 415 & 415 & 229 & 229 \\
\hline \multirow[t]{5}{*}{1950} & Mean & 0.3452313 & 0.254065 & 0.2088538 & $32,005.15$ \\
\hline & St. dev. & 0.4523494 & 0.7459898 & 0.1448257 & $73,305.76$ \\
\hline & Min. & 0 & -1 & 0.0001114 & 2,774 \\
\hline & Max. & 1 & 1 & 0.7235112 & $949,708.4$ \\
\hline & $N$ obs. & 486 & 492 & 492 & 492 \\
\hline \multirow[t]{5}{*}{1960} & Mean & 0.2539517 & 0.2642643 & 0.1941368 & $34,242.28$ \\
\hline & St. dev. & 0.4137504 & 0.6755555 & 0.1454932 & $82,867.91$ \\
\hline & Min. & 0 & -1 & 0 & $3,202.001$ \\
\hline & Max. & 1 & 1 & 0.6946776 & $939,023.6$ \\
\hline & $N$ obs. & 656 & 666 & 663 & 663 \\
\hline \multirow[t]{5}{*}{1970} & Mean & 0.1613318 & 0.2837259 & 0.1779699 & $29,274.97$ \\
\hline & St. dev. & 0.3543261 & 0.5554105 & 0.150278 & $79,091.1$ \\
\hline & Min. & 0 & -1 & 0 & 2,406 \\
\hline & Max. & 1 & 1 & 0.7703364 & $1,199,388$ \\
\hline & $N$ obs. & 904 & 934 & 936 & 936 \\
\hline \multirow[t]{5}{*}{1980} & Mean & 0.1721898 & 0.4061962 & 0.1825356 & $21,936.64$ \\
\hline & St. dev. & 0.3517008 & 0.536582 & 0.1646552 & $74,266.77$ \\
\hline & Min. & 0 & -1 & 0 & 113 \\
\hline & Max. & 1 & 1 & 0.9988168 & $1,595,138$ \\
\hline & $N$ obs. & 1,073 & 1,162 & 1,146 & 1,162 \\
\hline \multirow[t]{5}{*}{1990} & Mean & 0.2301296 & 0.3983558 & 0.2088375 & $20,532.95$ \\
\hline & St. dev. & 0.3838137 & 0.5150512 & 0.1756844 & $53,238.92$ \\
\hline & Min. & 0 & -1 & 0 & 243 \\
\hline & Max. & 1 & 1 & 0.9864677 & $935,926.6$ \\
\hline & $N$ obs. & 1,072 & 1,338 & 1,299 & 1,338 \\
\hline \multirow[t]{5}{*}{2000} & Mean & 0.318919 & 0.3225517 & 0.2462236 & $24,421.92$ \\
\hline & St. dev. & 0.4229846 & 0.5082095 & 0.1855629 & $89,530.48$ \\
\hline & Min. & 0 & -1 & 0 & 138 \\
\hline & Max. & 1 & 1 & 0.9933691 & $1,954,847$ \\
\hline & $N$ obs. & 1,010 & 1,113 & 1,113 & 1,113 \\
\hline \multirow[t]{5}{*}{ Total } & Mean & 0.2454504 & 0.3385301 & 0.2055153 & $26,973.67$ \\
\hline & St. dev. & 0.4016687 & 0.5937366 & 0.1662955 & $76,418.88$ \\
\hline & Min. & 0 & -1 & 0 & 113 \\
\hline & Max. & 1 & 1 & 0.9988168 & $1,954,847$ \\
\hline & $N$ obs. & 5,760 & 6,286 & 6,015 & 6,070 \\
\hline
\end{tabular}


Graduate School of Business, University of Chicago

DEPARTMENT OF ECONOMICS, HARVARD UNIVERSITY AND CANADIAN INSTITUTE FOR

ADVANCED RESEARCH

Department of Economics, Harvard University, National Bureau of Economic

Research, and Centre for Economic Policy Research

\section{REFERENCES}

Acemoglu, Daron, and James Robinson, Economic Origins of Dictatorship and Democracy (New York: Cambridge University Press, 2006).

Aghion, Philippe, Alberto Alesina, and Francesco Trebbi, "Endogenous Political Institutions," Quarterly Journal of Economics, 119 (May 2004), 565-612.

Aghion, Philippe, and Patrick Bolton, "Incomplete Social Contracts," Journal of the European Economic Association, 1 (2003), 38-67.

Alesina, Alberto, Reza Baqir, and Caroline Hoxby, "Political Jurisdictions in Heterogeneous Communities," Journal of Political Economy, 112 (April 2004), 348-396.

Alesina, Alberto, and Edward Glaeser, Fighting Poverty in the US and Europe: A World of Difference (Oxford: Oxford University Press, 2004).

Alesina, Alberto, and Howard Rosenthal, Partisan Politics, Divided Government, and the Economy (Cambridge, UK: Cambridge University Press, 1995).

Alexander, Gerard, "France: Reform-Mongering between Majority Runoff and Proportionality," in Handbook of Electoral System Choice, Josep M. Colomer, ed. (New York: Palgrave MacMillan, 2004).

Alt, James E., and Robert C. Lowry, "Divided Government, Fiscal Institutions and Budget Deficits: Evidence from the States," American Political Science Review, 89 (December 1994), 811-828.

Amy, Douglas J., Real Choices / New Voices: The Case for Proportional Representation Elections in the United States, 2nd ed. (New York: Columbia University Press, 2002).

Arellano, Manuel, and Stephen Bond, "Some Tests of Specification for Panel Data: Monte Carlo Evidence and an Application to Employment Equations," Review of Economics Studies, 58 (January 1991), 277-297.

Baqir, Reza, "Districting and Government Overspending," Journal of Political Economy, 110 (December 2002), 1318-1354.

Bohn, Henning, and Robert P. Inman, "Balanced Budget Rules and Public Deficits: Evidence from US States," Carnegie Rochester Conference on Public Policies, 13-76, 1996.

Buchanan, James M., and Gordon Tullock, The Calculus of Consent: Logical Foundations of Constitutional Democracy (Ann Arbor, MI: University of Michigan Press, 1962).

Cameron, Charles, David Epstein, and Sharyn O'Halloran, "Do Majority-Minority Districts Maximize Substantive Black Representation in Congress?" American Political Science Review, 90 (December 1996), 794-812.

Cole, Leonard A., Blacks in Power: A Comparative Study of Black and White Elected Officials (Princeton, NJ: Princeton University Press, 1976).

Colomer, Josep M., Handbook of Electoral System Choice (New York: Palgrave MacMillan, 2004).

Cox, Gary W., and Jonathan N. Katz, Elbridge Gerry's Salamander (Cambridge, UK: Cambridge University Press, 2002).

Cutler, David, Edward Glaeser, and Jacob Vigdor, "The Rise and Decline of the American Ghetto," Journal of Political Economy, 107 (June 1999), 455-506.

DeSantis, Victor, and Tari Renner, "Minority and Gender Representation In American County Legislatures: The Effect of Election Systems" in United States Electoral Systems, Wilma Rule, and Joseph F. Zimmerman, eds. (New York: Greenwood Press, 1992).

Friedman, John N., and Richard Holden, "Towards a Theory of Optimal Partisan Gerrymandering," mimeograph, Harvard University, 2005.

Grofman B., and C. Davidson, Controversies in Minority Voting (Washington, DC: Brookings Institution, 1992). 
Grofman, Bernard, Lisa Handley, and Richard Niemi, Minority Representation and the Quest for Voting Equality (New York: Cambridge University Press, 1992).

Hacker, Andrew, Two Nations: Black and White, Separate, Hostile, Unequal (New York: Scribner's, 1992).

Hayek, Friedrich A., The Constitution of Liberty (Chicago: University of Chicago Press, 1960).

Huckfeld, Robert, and Carol Weitzel Kohfeld, Race and the Decline of Class in American Politics (Urbana, IL: University of Illinois Press, 1989).

Kousser, Morgan J., Color-Blind Injustice: Minority Voting Rights and the Undoing of the Second Reconstruction (Chapel Hill, NC: University of North Carolina Press, 1999).

Kreuzer, Marcus, "Germany: Partisan Engineering of Personalized Proportional Representation," in Handbook of Electoral System Choice, Josep M. Colomer, ed. (New York: Palgrave MacMillan, 2004).

Laffont, Jean-Jacques, Incentives and Political Economy (New York: Oxford University Press, 2000).

Lijphart, Arend, Electoral Systems and Party Systems: A Study of 27 Democracies (New York: Oxford University Press, 1994).

Lipset, Seymour M., and Stein, Rokkan, Party Systems and Voter Alignments (New York: Free Press, 1967).

Mulligan, Casey B., Richard Gil, and Xavier Sala-i-Martin, "Do Democracies Have Different Public Policies than Nondemocracies?" Journal of Economic Perspectives, 18 (Winter 2004), 51-74.

Pande, Rohini, "Can Mandated Political Representation Increase Policy Influence for Disadvantaged Minorities? Theory and Evidence from India," American Economic Review, 93 (2003), 1132-1151.

Parker, F., Black Votes Count: Political Empowerment in Mississippi after 1965 (Chapell Hill, NC: University of North Carolina Press, 1990).

Persson, Torsten, and Guido Tabellini, The Economic Effects of Constitutions (Cambridge, MA: MIT Press, 2003).

Poterba, James M., "State Response on Fiscal Crises: The Effects of Budgetary Institutions on Policies," Journal of Political Economy, 102 (August 1994), 799-821.

Riker, William, The Art of Political Manipulation (New Haven, CT: Yale University Press, 1986).

Sass, Tim R., and Bobby J. Pittman, "The Changing Impact of Electoral Structure on Black Representation in the South, 1970-1996," Public Choice, 104, 3-4 (September 2000), 369-388.

Voigt, Stefan, "Positive Constitutional Economics: A Survey," Public Choice, 90 (March 1997), 11-53.

Wilson, William J., When Work Disappears: The World of the New Urban Poor (New York: Knopf, 1996). 
Copyright of Quarterly Journal of Economics is the property of MIT Press and its content may not be copied or emailed to multiple sites or posted to a listserv without the copyright holder's express written permission. However, users may print, download, or email articles for individual use. 